\title{
Streptococcus suis serotype 2 mutants deficient in capsular expression
}

\author{
Nathalie Charland, ${ }^{1}$ Josée Harel, ${ }^{1}$ Marylène Kobisch, ${ }^{2}$ Serge Lacasse ${ }^{1}$ \\ and Marcelo Gottschalk ${ }^{1}$
}

Author for correspondence: Marcelo Gottschalk. Tel: +1 5147738521 ext. 8374. Fax: +1 5147788108 . e-mail: gottschm@ere.umontreal.ca

1 Groupe de Recherche sur les Maladies Infectieuses du Porc, Faculté de médecine vétérinaire, Université de Montréal, CP 5000, St-Hyacinthe, Québec, Canada J2S 7C6

2 Centre National d'Études Vétérinaires et

Alimentaires, Unité Mycoplasmologie

Bactériologie, BP 53,

Zoopôle, 22440

Ploufragan, France
Streptococcus suis serotype 2 is responsible for a wide variety of porcine infections. In addition, it is considered a zoonotic agent. Knowledge about the virulence factors for this bacterium is limited but its polysaccharide capsule is thought to be one of the most important. Transposon mutagenesis with the self-conjugative transposon Tn916 was used to obtain acapsular mutants from the virulent S. suis type 2 reference strain S735. Clones were screened by colony-dot ELISA with a monoclonal antibody specific for a type 2 capsular epitope and clones that failed to react with the antibody were characterized. Two mutants, 2A and 79, having one and two In916 insertions respectively, were chosen for further characterization. Absence of capsule was confirmed by coagglutination, capillary precipitation and capsular reaction tests and by transmission electron microscopy. Absence of capsular polysaccharides correlated with increased hydrophobicity and phagocytosis by both murine macrophages and porcine monocytes compared to the wild-type strain. Furthermore, both mutants were shown to be avirulent in murine and pig models of infection. Finally, mutant 2A was readily eliminated from circulation in mice compared to the wild-type strain, which persisted more than $48 \mathrm{~h}$ in blood. Thus, isogenic mutants defective in capsule production demonstrate the importance of capsular polysaccharides as a virulence factor for S. suis type 2.

Keywords: Streptococcus suis, Tn916, capsule, mutant, virulence

\section{INTRODUCTION}

Streptococcus suis is responsible for a wide variety of porcine disease syndromes, such as meningitis, septicaemia, arthritis and endocarditis (Higgins \& Gottschalk, 1998). It is also recognized as a human pathogen, causing mainly meningitis (with deafness as a common sequela) and endocarditis (Walsh et al., 1992; Arends \& Zanen, 1988; Trottier et al., 1991). To date, 35 serotypes of $S$. suis have been described, with serotype 2 being the most frequently isolated from diseased animals (Higgins \& Gottschalk, 1996). Knowledge on virulence factors of $S$. suis is limited. Several virulence factor candidates have been proposed. These include the polysaccharide capsule, cell-wall and extracellular proteins, including muramidase-released protein

\footnotetext{
Abbreviations: DIG, digoxigenin; EF, extracellular factor; FBS, foetal bovine serum; MRP, muramidase-released protein; NANA, $N$-acetylneuraminic acid (sialic acid); SNA I, Sambucus nigra agglutinin ; SPF, specific-
} pathogen free.
(MRP), extracellular factor (EF) and adhesins, and a haemolysin (Gottschalk et al., 1995; Jacobs et al., 1994; Tikkanen et al., 1996; Vecht et al., 1991). Recent studies have shown that $S$. suis mutants which produce neither MRP nor EF are as virulent as the wild-type strain (Smith et al., 1996). It has been suggested that these proteins could be used as virulence markers for European strains. On the other hand, most field strains isolated in Canada do not produce these proteins and/or the haemolysin (Gottschalk et al., 1998).

Although the polysaccharide capsule of $S$. suis serotype 2 , which contains, among other sugars, a sialic acid moiety (Elliott \& Tai, 1978; Katsumi et al., 1996), has been identified as a potential virulence factor, its role in the pathogenesis of the infection can be considered controversial. It has been shown that, with some exceptions (Elliott et al., 1980), both virulent and avirulent strains are encapsulated and are similarly phagocytosed by macrophages, and that the capsule of an avirulent strain does not appear to aid intracellular survival (Brazeau et al., 1996; Williams, 1990). In 
addition, sialic acid does not seem to be critical for virulence, since all field strains of $S$. suis serotype 2 tested had the same low sialic acid concentration regardless of their virulence, and blocking or enzymic removal of this sugar did not influence phagocytosis rates and virulence of a virulent strain (Charland et al., 1996). On the other hand, a spontaneous unencapsulated mutant, obtained from a virulent strain by serial passages in presence of anti-capsular antibodies, was shown to be avirulent in mice (Gottschalk et al., 1992) and highly phagocytosed (Brazeau et al., 1996; Salasia et al., 1995). However, this mutant also lacked, at least, a $44 \mathrm{kDa}$ cell-wall protein. The claim that the presence of a capsule is required for virulence awaited testing with isogenic mutants.

Transposon mutagenesis is a powerful tool used to evaluate the involvement of specific factors in the pathogenesis of streptococci (Caparon \& Scott, 1991). It has successfully been used to produce unencapsulated mutants of group B streptococci (Rubens et al., 1987). This paper describes the production and characterization of $S$. suis serotype 2 mutants deficient in the expression of the polysaccharide capsule obtained using the self-conjugative transposon $\operatorname{Tn} 916$.

\section{METHODS}

Bacterial strains and culture conditions. The well-encapsulated $S$. suis serotype 2 reference strain $S 735$ (kindly provided by $\mathrm{Dr}$ J. Henrichsen, Statens SerumInstitut, Copenhagen, Denmark) was used as the recipient strain for transposon mutagenesis. This strain, which is susceptible to both tetracycline and streptomycin, was rendered resistant to the latter by serial passages in Todd-Hewitt broth (THB; Difco) containing increasing streptomycin concentrations and was named S735-SM. Enterococcus faecalis CG110 (kindly supplied by Dr C. E. Rubens, Children's Hospital and Medical Center, Seattle, WA, USA), which contains Tn916, a $18 \mathrm{~kb}$ transposon encoding tetracycline resistance (Gawron-Burke \& Clewell, 1984), was used as the donor strain and grown in THB containing $10 \mu \mathrm{g}$ tetracycline $\mathrm{ml}^{-1}$. Escherichia coli CG120 (kindly provided by Dr D. B. Clewell, University of Michigan, Ann Arbor, MI, USA), possessing plasmid pAM120 encoding ampicillin resistance and containing Tn916 (Gawron-Burke \& Clewell, 1984), was grown in THB with $10 \mu \mathrm{g}$ tetracycline and $50 \mu \mathrm{g}$ ampicillin $\mathrm{ml}^{-1}$, and was used for probe preparation.

Transposon mutagenesis. Plate mating between the two strains was done by the method of Caparon \& Scott (1991) with the ratio of donor to recipient changed to $1: 100$. Briefly, Enterococcus faecalis CG110, in $5 \mathrm{ml}$ THB containing $10 \mu \mathrm{g}$ tetracycline $\mathrm{ml}^{-1}$, and S. suis S735-SM, in $100 \mathrm{ml}$ THB supplemented with $2 \mathrm{~g}$ yeast extract $\mathrm{I}^{-1}$, were grown overnight at $37^{\circ} \mathrm{C}$. Both suspensions were centrifuged, washed three times, resuspended in THB and strain S735-SM mixed with CG110. Spots of the mixed suspension were plated onto bovine blood agar plates and left to incubate overnight at $37^{\circ} \mathrm{C}$. Growth was retrieved by washing the plates with PBS (140 mM NaCl, $3 \mathrm{mM} \mathrm{KCl}, 10 \mathrm{mM} \mathrm{Na}{ }_{2} \mathrm{HPO}_{4}, 1.5 \mathrm{mM}$ $\mathrm{KH}_{2} \mathrm{PO}_{4}$, $\mathrm{pH} 7 \cdot 4$ ). The suspension was centrifuged, resuspended in PBS and plated onto Todd-Hewitt agar (THA) plates containing $800 \mu \mathrm{g}$ streptomycin $\mathrm{ml}^{-1}$ and $10 \mu \mathrm{g}$ tetracycline $\mathrm{ml}^{-1}$. Plates were incubated for $24-36 \mathrm{~h}$ at $37^{\circ} \mathrm{C}$ and transconjugants transferred on new selective plates. Conjugation frequency was calculated by dividing the number of Tn916-containing colonies resistant to both streptomycin and tetracycline by the total number of potential recipient colonies resistant only to streptomycin.

Screening of transconjugants. Screening was done by colony dot of transconjugants as described by Rioux et al. (1997) using a monoclonal antibody, $\mathrm{mAb} \mathrm{Z3}$, specific for a serotype 2 sialic-acid-containing capsular epitope (Charland et al., 1997). Failure of colonies to react with mAb Z3 could be due either to the absence of sialic acid or to the absence of all capsular polysaccharides.

Preparation of digoxigenin-labelled Tn916 probe and DNADNA hybridization. Total cellular DNA was first isolated by the method of Sambrook et al. (1989). To perform Southern blot DNA-DNA hybridization analysis (Nizet et al., 1996), a Tn916 probe labelled with digoxigenin (DIG) was prepared using the Boehringer Mannheim DIG DNA labelling and detection kit. The EcoRI fragment of plasmid pAM120 containing Tn916 was isolated from low-melting-point agarose as described by Sambrook et al. (1989). The DIGlabelled $\mathrm{Tn} 916$ was used to probe EcoRI and $S c a$ I digests of whole-cell DNA as described by the manufacturer.

\section{Characterization of mutants}

Biochemical identification of mutants. Mutants were confirmed biochemically to be $S$. suis by standard identification techniques (Higgins \& Gottschalk, 1990).

Production of haemolysin, MRP and EF. Production of haemolysin was tested as described previously (Gottschalk et al., 1995). Production of MRP and EF was tested as described by Vecht et al. (1991).

Sialic acid determination tests. An agglutination test with a sialicacid-binding lectin from Sambucus nigra, SNA I, known to react with the sialic acid moiety of $S$. suis serotype 2 capsule (Charland et al., 1995), was used as a screening test to identify capsule deficient mutants. Presence of $\mathrm{N}$-acetylneuraminic acid (NANA) was shown by coarse aggregates. Absence of NANA was confirmed by the thiobarbituric acid assay (Warren, 1963).

Serotyping of mutants. Serotyping was carried out by three different techniques. Coagglutination, capillary precipitation and capsular reaction tests utilized specific type 2 antiserum as previously described (Higgins \& Gottschalk, 1990).

Transmission electron microscopy. Transmission electron microscopy after immunostabilization was carried out as described by Jacques et al. (1990). Briefly, wild-type as well as mutant strains were mixed with specific type 2 antiserum or with normal serum as a negative control. Bacterial suspensions were adjusted to $\mathrm{OD}_{540} 1.8$ and exposed to undiluted polyclonal or normal sera for $1 \mathrm{~h}$ at $4{ }^{\circ} \mathrm{C}$. Bacterial cells were then suspended in $0 \cdot 1 \mathrm{M}$ cacodylate buffer, $\mathrm{pH} 7 \cdot 0$, containing $5 \%(\mathrm{v} / \mathrm{v})$ glutaraldehyde and $0 \cdot 15 \%(\mathrm{w} / \mathrm{v})$ ruthenium red. Fixation was for $2 \mathrm{~h}$ at $20^{\circ} \mathrm{C}$. Cells were then immobilized in $4 \%(\mathrm{w} / \mathrm{v})$ agar, washed five times in cacodylate buffer plus $0.05 \%$ ruthenium red, and postfixed with $2 \%$ (v/v) osmium tetroxide for $2 \mathrm{~h}$. Samples were washed as above and dehydrated in a graded series of acetone washes containing $0.05 \%$ ruthenium red. Specimens were then washed twice in propylene oxide and embedded in Spurr low-viscosity resin. Thin sections were poststained with uranyl acetate and lead citrate and examined with an electron microscope (Philips 201) at an accelerating voltage of $60 \mathrm{kV}$. 
Hydrophobicity test. Hydrophobicity was measured using the nhexadecane method (Rosenberg, 1984).

Phagocytic assays. Phagocytic cells were retrieved from the peritoneal cavity of mice or from pig blood and left to adhere on microscope slides as described by Brazeau et al. (1996) and Charland et al. (1996). Bacteria were added to a ratio of 10 bacteria to 1 phagocyte and incubated for $1 \mathrm{~h}$ at $37^{\circ} \mathrm{C}, 5 \%$ $\mathrm{CO}_{2}$. After incubation, cells were stained with the vital dye acridine orange and counterstained with crystal violet, so that only engulfed bacteria were visible under UV light (Williams, 1990). The assay was repeated in three independent experiments. Percentages of phagocytosis were calculated as: (no. of phagocytes with engulfed bacteria divided by 200 examined phagocytes) $\times 100$ (Charland et al., 1996).

Virulence assays. Virulence was assessed in mice and piglets. To measure the $\mathrm{LD}_{50}$ in mice, bacteria were grown for $6 \mathrm{~h}$ in THB supplemented with $10 \%$ heat-inactivated foetal bovine serum (FBS). For each strain, five groups of five BALB/c mice 4-6 weeks old were injected intraperitoneally with $1 \mathrm{ml}$ per mouse of undiluted bacterial suspension or tenfold dilutions in THBFBS of the original suspension. Mortality was monitored over a week and the $\mathrm{LD}_{50}$ of each strain calculated by the method of Reed \& Muench (1938). An experimental infection in swine was also carried out. Three groups of seven specific-pathogenfree (SPF) piglets 6-7 weeks old, naturally born from hysterectomy-derived sows, were used (one group per strain) and kept in high-security barns. Bacteria were grown in THBFBS for $5 \mathrm{~h}$ at $37^{\circ} \mathrm{C}$ and the $\mathrm{OD}_{600}$ of the suspension adjusted to $0 \cdot 15$, which corresponds to about $10^{8}$ c.f.u. $\mathrm{ml}^{-1}$. Piglets were injected intravenously with $1 \mathrm{ml}$ of the suspension. Clinical signs were monitored daily and pigs were killed either if severely sick or, if they presented no signs, one week after infection. Autopsies were performed on each piglet with macroscopic, bacteriological and/or histological examinations of affected tissues.

Bacterial clearance test. Bacteria were grown as for the virulence assay except that suspensions were adjusted to a concentration of $3 \times 10^{6}$ c.f.u. $\mathrm{ml}^{-1}$ in THB-FBS to prevent mortality. Groups of seven mice were injected intraperitoneally with $1 \mathrm{ml}$ bacterial suspension. Mice were killed by cervical dislocation at various time intervals after injection, blood samples taken from hearts and viable counts performed on blood agar plates. The assay was repeated in three independent experiments.

\section{RESULTS AND DISCUSSION}

\section{Characterization of mutants deficient in capsular expression}

Tn916 was transferred from Enterococcus faecalis CG110 to S735-SM at a frequency of 1 per $1.5 \times 10^{6}$ recipient cells, which is in the range of conjugation frequency obtained with Streptococcus pyogenes (Caparon \& Scott, 1987). More than 8000 clones were screened and, of these, seven mutants did not present any reaction with $\mathrm{mAb} \mathrm{Z} 3$.

After preliminary testing of these clones based on the number of transposon insertions and capsule production, two mutants, named $2 \mathrm{~A}$ and 79 , were selected for further characterization. Both mutants were shown to be biochemically identical to the wild-type strain. In addition, the production of other putative virulence factors of $S$. suis such as haemolysin, MRP and EF was not affected by transposition (Table 1 ). Since mAb Z3 is specific for a sialic-acid-containing epitope, mutants were tested for the presence of NANA. Fine aggregates were seen in the reaction between both mutants and the lectin SNA I compared to coarse ones with the wild-type strain. In addition, NANA concentration was shown to be very low in both mutants (Table 1). Serotyping, which is indicative of the presence of a capsule, was carried out by three different techniques. Mutants reacted only weakly by coagglutination with specific type 2 antiserum compared to the wild-type strain S735SM, indicating little capsule expression or reaction with other surface antigens. Capillary precipitation and capsular reaction tests, which are more specific for the detection of capsular antigens, were negative for both mutants (Table 1).

To confirm the absence or altered expression of capsule on mutants, both of the mutants and the wild-type strain were examined by transmission electron microscopy. No or very little capsular material seemed to be present on cell surfaces of mutants $2 \mathrm{~A}$ (Fig. 1c) and 79 (not shown) after immunostabilization of the capsule. The absence of sialic acid implies the probable absence of the complete capsule since it has been suggested that, after complete removal of the sialic acid moiety, a reaction with anti-type 2 serum is not detected (Katsumi et al., 1996). This would also correlate with the absence of immunostabilization. Katsumi et al. (1996) mentioned that the sialic acid residue in the capsule of $S$. suis serotype 2 is probably the exact epitope component.

\section{Molecular characterization of mutants}

To determine the number of $\operatorname{Tn} 916$ insertions in each mutant, total DNA was extracted and cut with EcoRI and ScaI. EcoRI does not cut within Tn916 whereas ScaI cuts only once (Flannagan et al., 1994). Southern blot DNA-DNA hybridization analysis, using DIG-labelled Tn916 to probe EcoRI and ScaI chromosomal digests of mutants, shows that mutant $2 \mathrm{~A}$ contained one (Fig. 2 lanes B and C) and mutant 79 two (lanes D and E) Tn916 insertions. No background hybridization was seen between wild-type DNA and the probe (Fig. 2, lane A). DNA adjacent to these insertions, after digestion with ScaI, was of $11.6 \mathrm{~kb}$ for mutant $2 \mathrm{~A}$, and of 11.6 and $12.7 \mathrm{~kb}$ for mutant 79 . As shown in Fig. 2, although mutant 79 seemed to have only one Tn916 insertion after digestion with EcoRI, Scal digestion showed another transposon insertion. It seems that only one transposon insertion is sufficient to alter capsular expression as seen for group B streptococci (Rubens et al., 1993, 1987).

\section{Influence of defective capsular expression on hydrophobicity and phagocytosis}

It has been shown that alteration of capsular expression can modify surface hydrophobicity and affect adherence on cells (Absolom, 1988). Influence of altered capsular expression on hydrophobicity and phagocytosis was tested (Table 1). Mutants $2 \mathrm{~A}$ and 79 demonstrated 
Table 1. Characterization of two S. suis serotype 2 mutants produced by transposition from reference strain S735-SM

For agglutination experiments, the capsular reaction test and the capillary precipitation test, the strength of the reaction is indicated as follows: +++ , strong reaction; + , weak reaction; - , no reaction. For phagocytosis experiments, pig monocyte-derived macrophages were used. Data for NANA concentration, hydrophobicity and phagocytosis are the means of three independent experiments $\pm S D$; results for the mutant strains were significantly different $(P<0.05)$ compared to the wild-type strain.

\begin{tabular}{|c|c|c|c|}
\hline Test & S735-SM & $2 \mathrm{~A}$ & 79 \\
\hline MRP protein & Yes & Yes & Yes \\
\hline EF protein & Yes & Yes & Yes \\
\hline Haemolysin & Yes & Yes & Yes \\
\hline SNA I agglutination & +++ & + & + \\
\hline NANA concentration & $4.07 \pm 1.42 \mu \mathrm{g} \mathrm{mg}^{-1}$ & $0 \cdot 11 \pm 0.04 \mu \mathrm{g} \mathrm{mg}^{-1}$ & $0 \cdot 10 \pm 0.03 \mu \mathrm{g} \mathrm{mg}^{-1}$ \\
\hline Coagglutination test & +++ & + & + \\
\hline Capsular reaction test & +++ & - & - \\
\hline Capillary precipitation test & +++ & - & - \\
\hline Hydrophobicity & $0.9 \pm 0.4 \%$ & $22 \cdot 0 \pm 0.9 \%$ & $17 \cdot 7 \pm 0 \cdot 8 \%$ \\
\hline Phagocytosis & $23 \pm 9 \%$ & $70 \pm 8 \%$ & $70 \pm 4 \%$ \\
\hline $\mathrm{LD}_{50}$ & $7 \times 10^{5}$ c.f.u. $\mathrm{g}^{-1}$ & $>7 \times 10^{7}$ c.f.u. $\mathrm{g}^{-1}$ & $>7 \times 10^{7}$ c.f.u. $\mathrm{g}^{-1}$ \\
\hline
\end{tabular}
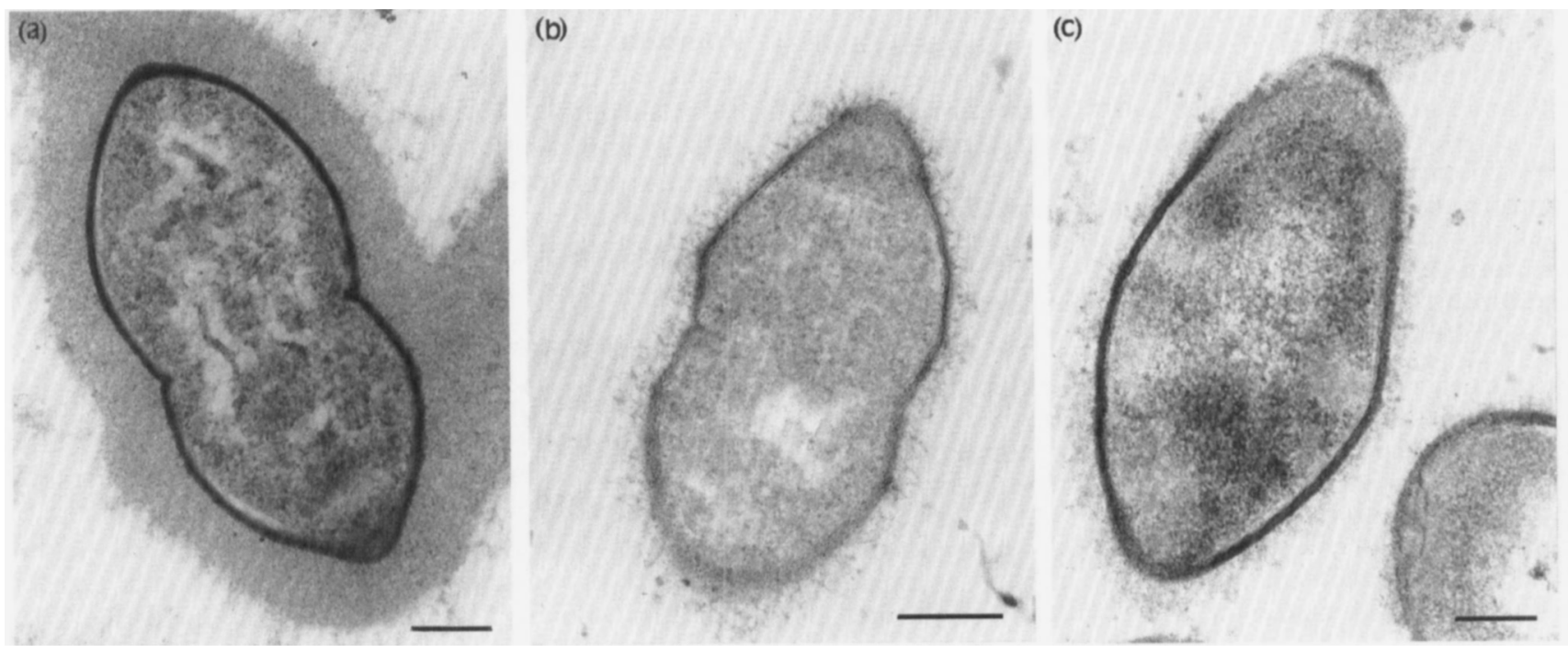

Fig. 1. Transmission electron micrographs of thin sections of Streptococcus suis serotype 2: (a) strain S735-SM stabilized with specific type 2 rabbit polyclonal antiserum, (b) strain S735-SM stabilized with normal rabbit serum (negative control) and (c) mutant $2 A$ stabilized with type 2 rabbit polyclonal antiserum. Results similar to (c) were obtained with mutant 79 , and results similar to (b) with both mutants. Bars, $200 \mathrm{~nm}$.

hydrophobicity at $22 \%$ and $17 \cdot 7 \%$ respectively, compared to $0.9 \%$ for $\mathrm{S} 735-\mathrm{SM}$, indicating that capsular polysaccharides are important to surface hydrophobicity of S. suis (Salasia et al., 1995). Percentages of phagocytosis by murine macrophages and porcine monocyte-derived macrophages were evaluated for the three strains. These phagocytic cells were chosen to provide a comparison of phagocytosis rates between the natural host's phagocytes and phagocytes from the animal model of choice for $S$. suis infections (Beaudoin et al., 1992; Williams et al., 1988). Table 1 shows that both mutants were significantly more phagocytosed than the wild-type strain by porcine phagocytic cells, with a mean number of 6 (S735-SM), 16 (mutant 2A) and 18 (mutant 79) phagocytosed organisms per phagocyte. Similar results were obtained with murine cells (data not shown). These results show that the presence of capsular polysaccharides prevents phagocytosis, which may help bacterial pathogenesis. Since capsular polysaccharide material confers a net negative charge on a bacterium, it is rendered hydrophilic (Moxon \& Kroll, 1990). Removal of capsular material increases the hydrophobic index, thereby increasing adherence and phagocytosis (Absolom, 1988). This seems to be the case for S. suis 


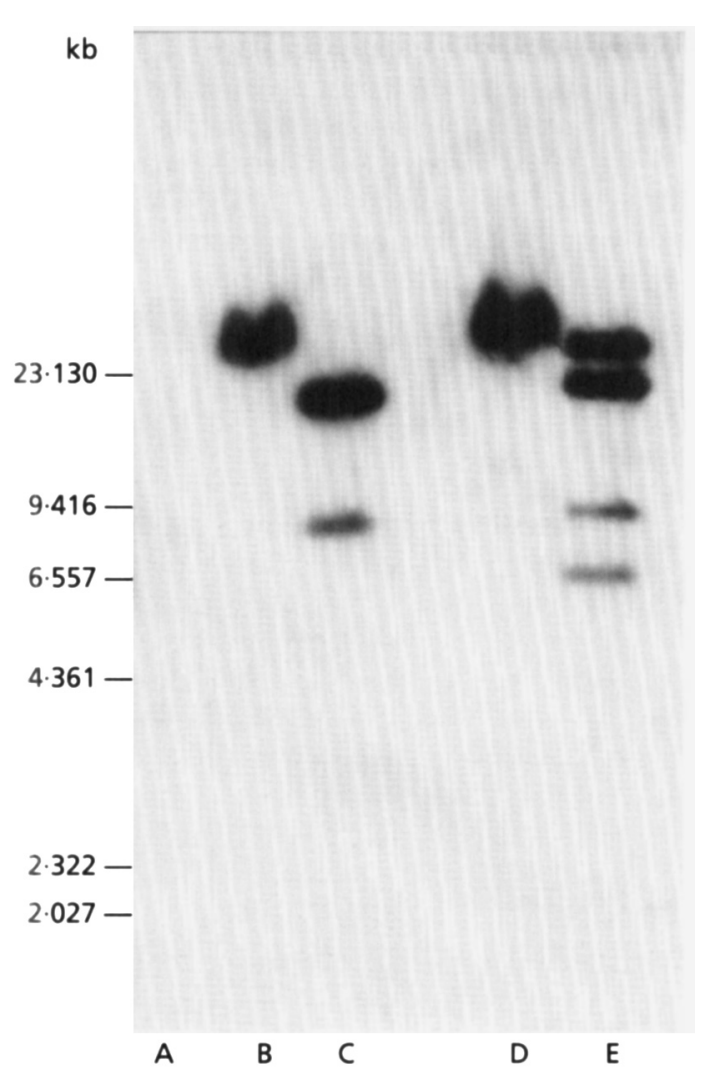

Fig. 2. Southern blot with DIG-labelled Tn916 of total cellular DNA. Lane A, DNA of strain S735-SM digested with EcoRI; lanes $B$ and $C$, DNA of mutant 2A digested with EcoRI (lane B) and Scal (lane C); lanes D and E, DNA of mutant 79 digested with EcoRI (lane D) and Scal (lane E). Molecular sizes of standards in $\mathrm{kb}$ are indicated. Image generated using a HP ScanJet IIc with PhotoFinish 2.0 software on a PC 486 DX.

unencapsulated mutants. In addition, Tikkanen et al. (1996) recently showed that the variable agglutinating activity of some $S$. suis strains was inversely propor- tional to the amount of capsular polysaccharides, which the authors suggest could mask adhesins.

\section{Influence of defective capsular expression on virulence and blood clearance}

Both mutants were more than 100 -fold less virulent for mice than the wild-type strain as shown by their $\mathrm{LD}_{50}$ of more than $7 \times 10^{7}$ c.f.u. $\mathrm{g}^{-1}$, compared to $7 \times 10^{5}$ c.f.u. $\mathrm{g}^{-1}$ for S735-SM (Table 1). For pig infection, Table 2 shows that all piglets injected with S735-SM presented with hyperthermy (i.e. at least $1{ }^{\circ} \mathrm{C}$ over the normal body temperature of $39.5^{\circ} \mathrm{C}$ for an SPF pig) and locomotive difficulties for at least $3 \mathrm{~d}$ post-infection. Forty-eight hours after injection, three piglets showing opisthotonos and paddling signs with elevated temperature were killed. These pigs showed suppurative meningitis at autopsy. $S$. suis serotype 2 was recovered from brains and/or from other organs of all seven pigs. Histological examinations of synovial membranes of some pigs showed an early inflammatory reaction. Piglets injected with both mutants showed no clinical signs. Animals of these groups were killed one week after infection. Autopsies did not reveal significant macroscopic or microscopic lesions. S. suis serotype 2 was isolated only from the synovial fluid of a knee in a pig injected with mutant 79 . The isolate was still tetracycline-resistant. No bacterium was isolated in any tonsils of these two groups. Isolation of the wild-type strain from many different organs of all infected pigs shows that the presence of capsular polysaccharides may help bacteria to disseminate and survive more easily. In fact, S735-SM could be isolated from its natural reservoir in pigs, the tonsils (Higgins \& Gottschalk, 1998), in all animals, whereas mutants could not be recovered from this site. Thus, the presence of capsular polysaccharides contributes to the virulence of S. suis serotype 2 in both mice and pigs.

Table 2. Experimental infection of SPF piglets with S. suis serotype 2 reference strain S735-SM and two serotype 2 mutants produced by transposition from strain S735-SM

\begin{tabular}{|lcllc|}
\hline Strain & $\begin{array}{c}\text { Dose }\left[10^{-8} \times\right. \\
\text { (c.f.u. } \mathrm{ml}^{-1} \text { ) } \\
\pm \text { SD }]\end{array}$ & Clinical signs & \multicolumn{1}{c|}{ Lesions } & Isolation \\
\hline S735-SM & $5 \cdot 3 \pm 1 \cdot 2$ & $\begin{array}{l}\text { Fever, } \\
\text { locomotive } \\
\text { difficulties* }\end{array}$ & $\begin{array}{l}\text { Suppurative meningitis, } \\
\text { early inflammatory } \\
\text { reaction of synovial } \\
\text { membranes } \dagger\end{array}$ & $7 / 7 \ddagger$ \\
Mutant 2A & $5 \cdot 7 \pm 1 \cdot 3$ & None & None & $0 / 7$ \\
Mutant 79 & $3 \cdot 6 \pm 1 \cdot 4$ & None & None & $1 / 7 \$$ \\
\hline
\end{tabular}

*All seven pigs of the group were affected.

†Three pigs with severe locomotive difficulties and paddling signs showed meningitis; two other pigs shows inflammation.

$¥$ Strain isolated from liver, spleen, lungs, heart, tonsils, brains and/or joints from all seven infected pigs.

\Isolated in synovial fuid from a knee of one pig. 


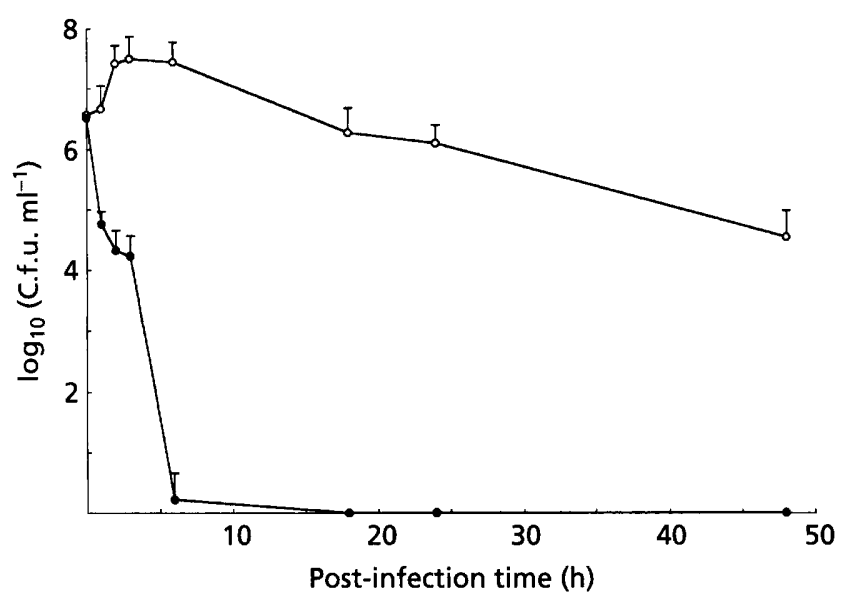

Fig. 3. Bacterial clearance in mice injected with $S$. suis serotype 2 strain S735-SM (O) and acapsular mutant 2A (O). The data are means of three experiments; error bars represent SD.

Bacterial clearance of the wild-type strain and mutant $2 \mathrm{~A}$ was tested in mice. Fig. 3 shows that the mutant is cleared rapidly from circulation compared to the wildtype strain. These results support those obtained from the virulence experiments where the mutants were reisolated unfrequently. In addition, clearance results are in agreement with those obtained by Clifton-Hadley (1981) who showed that a less encapsulated variant of a $S$. suis type 2 strain was readily cleared from pig blood.

Capsules have been shown to have a key role in host-pathogen interactions (Moxon \& Kroll, 1990). Unencapsulated mutants of bacteria involved in invasive infections, such as group A and B streptococci (Wessels et al., 1991; Rubens et al., 1987) or Escherichia coli K-1 (Kim et al., 1992), have demonstrated the critical role of the capsule in virulence. One means by which a bacterium disseminates through a host is by evading the immune system (Moxon \& Kroll, 1990) and many encapsulated bacteria have been shown to possess antiphagocytic properties (Dale et al., 1996; Kasper, 1986; Martin et al., 1992). Previous studies with spontaneous, genetically uncharacterized $S$. suis serotype 2 mutants suggested that loss or alteration of capsule expression could influence the fate of the bacterium in a host (Brazeau et al., 1996; Gottschalk et al., 1992). Results reported here show that isogenic mutants with specific mutations which preclude capsular expression are avirulent and cleared rapidly from circulation compared to the wild-type strain, clarifying the ambiguous role of the capsule in the virulence of $S$. suis for both mice and pigs. To our knowledge, the capsule of $S$. suis serotype 2 is the first critical virulence factor described so far for this bacterium.

It is clear, however, that the capsule of $S$. suis serotype 2 cannot be the only factor for virulence since it is known that serotype 2 avirulent field strains are encapsulated (Beaudoin et al., 1992; Quessy et al., 1995). In fact, a monoclonal antibody against a capsular epitope of $S$. suis serotype 2 reference strain could not protect mice completely from a lethal dose of bacteria (Charland et al., 1997). Other factors, such as extracellular or cellwall-associated proteins, are probably required for successful establishment of the bacteria in the host. The role of the capsule may be, for example, to protect $S$. suis from phagocytosis while it produces its toxic components.

\section{Concluding remarks}

Isogenic mutants of $S$. suis serotype 2 deficient in capsule expression were produced by transposon mutagenesis. These mutants were more hydrophobic and more susceptible to phagocytosis by mouse and pig phagocytes than the wild-type strain. In addition, they were avirulent for both mice and piglets in challenge experiments and cleared from circulation rapidly. Characterization of the insertion site is currently in progress.

\section{ACKNOWLEDGEMENTS}

We are grateful to $\mathrm{Dr}$ J. Henrichsen for confirmation of the capsular reaction test and to $\mathrm{Dr} M$. Jacques for the transmission electron micrographs. We also wish to thank $\mathrm{S}$. Lacouture, B. Chevallier, A. Mesplède, A. Keranflec'h, R. Cariolet and the Laboratoire Départemental d'Analyses of Ploufragan for excellent technical assistance and Dr C. E. Rubens for interesting discussions. This work was supported by Grant 0GP0154280 from the Natural Sciences and Engineering Research Council of Canada (NSERC) and Grant 98-NC-1037 from the Fonds pour la Formation des Chercheurs et l'Aide à la Recherche. N.C. is the recipient of an NSERC scholarship.

\section{REFERENCES}

Absolom, R. (1988). The role of bacterial hydrophobicity in infection: bacterial adhesion and phagocytic ingestion. Can J Microbiol 34, 287-298.

Arends, J. P. \& Zanen, H. (1988). Meningitis caused by Streptococcus suis in humans. Rev Infect Dis 10, 131-137.

Beaudoin, M., Higgins, R., Harel, J. \& Gottschalk, M. (1992). Studies on a murine model for evaluation of virulence of Streptococcus suis capsular type 2 isolates. FEMS Microbiol Lett 78, 111-116.

Brazeau, C., Vincelette, S., Gottschalk, M. \& Martineau-Doizé, B. (1996). In vitro phagocytosis and survival of Streptococcus suis capsular type 2 inside murine macrophages. Microbiology 142, 1231-1237.

Caparon, M. G. \& Scott, J. R. (1987). Identification of a gene that regulates expression of $M$ protein, the major virulence determinant of group A streptococci. Proc Natl Acad Sci USA 84, 8677-86.

Caparon, M. G. \& Scott, J. R. (1991). Genetic manipulation of pathogenic streptococci. Methods Enzymol 204, 556-586.

Charland, N., Kellens, J. T. C., Caya, F. \& Gottschalk, M. (1995). Agglutination of Streptococcus suis by sialic acid-binding lectins. J Clin Microbiol 33, 2220-2221.

Charland, N., Kobisch, M., Martineau-Doizé, B., Jacques, M. \& 
Gottschalk, M. (1996). Role of capsular sialic acid in virulence and resistance to phagocytosis of Streptococcus suis capsular type 2. FEMS Immunol Med Microbiol 14, 195-203.

Charland, N., Jacques, M., Lacouture, S. \& Gottschalk, M. (1997). Characterization and protective activity of a monoclonal antibody against a capsular epitope shared by Streptococcus suis serotypes 1, 2 and 1/2. Microbiology 143, 3607-3614.

Clifton-Hadley, F. A. (1981). Studies of Streptococcus suis type 2 infection in pigs. $\mathrm{PhD}$ thesis, University of Cambridge.

Dale, J. B., Washburn, R. G., Marques, M. B. \& Wessels, M. R. (1996). Hyaluronate capsule and surface $M$ protein in resistance to opsonization of group A streptococci. Infect Immun 64, 1495-1501.

Elliott, S. D. \& Tai, J. (1978). The type-specific polysaccharides of Streptococcus suis. J Exp Med 148, 1699-1704.

Elliott, S. D., Clifton-Hadley, F. A. \& Tai, J. (1980). Streptococcal infection in young pigs. V. An immunogenic polysaccharide from Streptococcus suis type 2 with particular reference to vaccination against streptococcal meningitis in pigs. J Hyg 85, 275-285.

Flannagan, S. E., Zitzow, L. A., Su, Y. A. \& Clewell, D. B. (1994). Nucleotide sequence of the $18-\mathrm{kb}$ conjugative transposon $\operatorname{Tn} 916$ from Enterococcus faecalis. Plasmid 32, 350-354.

Gawron-Burke, C. \& Clewell, D. B. (1984). Regeneration of insertionally inactivated streptococcal DNA fragments after excision of transposon Tn916 in Escherichia coli: strategy for targeting and cloning of genes from Gram-positive bacteria. $J$ Bacteriol 159, 214-221.

Gottschalk, M., Higgins, R., Jacques, M. \& Dubreuil, D. (1992). Production and characterization of two Streptococcus suis capsular type 2 mutants. Vet Microbiol 30, 59-71.

Gottschalk, M., Lacouture, S. \& Dubreuil, J. D. (1995). Characterization of Streptococcus suis capsular type 2 haemolysin. Microbiology 141, 189-195.

Gottschalk, M., Lebrun, A., Wisselink, H., Dubreuil, J. D., Smith, H. \& Vecht, U. (1998). Production of virulence-related proteins by Canadian strains of Streptococcus suis capsular type 2. Can J Vet Res 62, 75-79.

Higgins, R. \& Gottschalk, M. (1990). An update on Streptococcus suis identification. J Vet Diagn Invest 2, 249-252.

Higgins, R. \& Gottschalk, M. (1996). Distribution of Streptococcus suis capsular types in 1995. Can Vet J 37, 242.

Higgins, R. \& Gottschalk, M. (1998). Streptococcal diseases. In Diseases of Swine, chapter 38. Iowa: Iowa State University Press (in press).

Jacobs, A. A. C., Loeffen, P. L. W., Van Den Berg, A. J. G. \& Storm, P. K. (1994). Identification, purification, and characterization of a thiol-activated hemolysin (suilysin) of Streptococcus suis. Infect Immun 62, 1742-1748.

Jacques, M., Gottschalk, M., Foiry, B. \& Higgins, R. (1990). Ultrastructural study of surface components of Streptococcus suis. J Bacteriol 172, 2833-2838.

Kasper, D. L. (1986). Bacterial capsule - old dogmas and new tricks. J Infect Dis 153, 407-415.

Katsumi, M., Saito, T., Kataoka, Y., Itoh, T., Kikuchi, N. \& Hiramune, T. (1996). Comparative preparation methods of sialylated capsule antigen from Streptococcus suis type 2 with type specific antigenicity. $J$ Vet Med Sci 58, 947-952.

Kim, K. S., Itabashi, H., Gemski, P., Sadoff, J., Warren, R. L. \& Cross, A. S. (1992). The K1 capsule is the critical determinant in the development of Escherichia coli meningitis in the rat. J Clin Invest 90, 897-905.
Martin, T. R., Ruzinski, J. T., Rubens, C. E., Chi, E. Y. \& Wilson, C. B. (1992). The effect of type-specific polysaccharide capsule on the clearance of group B streptococci from the lungs of infant and adult rats. J Infect Dis 165, 306-314.

Moxon, E. R. \& Kroll, J. S. (1990). The role of bacterial polysaccharide capsules as virulence factors. Curr Top Microbiol Immunol 150, 65-85.

Nizet, V., Gibson, R. L., Chi, E. Y., Framson, P. E., Hulse, M. \& Rubens, C. E. (1996). Group B streptococcal beta-hemolysin expression is associated with injury of lung epithelial cells. Infect Immun 64, 3818-3826.

Quessy, S., Dubreuil, J. D., Caya, M. \& Higgins, R. (1995). Discrimination of virulent and avirulent Streptococcus suis capsular type 2 isolates from different geographical origins. Infect Immun 63, 1975-1979.

Reed, L. J. \& Muench, H. (1938). A simple method of estimating the fifty percent endpoints. Am J Hyg 27, 493-497.

Rioux, S., Bégin, C., Dubreuil, J. D. \& Jacques, M. (1997). Isolation and characterization of LPS mutants of Actinobacillus pleuropneumoniae serotype 1. Curr Microbiol 35, 139-144.

Rosenberg, M. (1984). Bacterial adherence to hydrocarbons: a useful technique for studying cell-surface hydrophobicity. FEMS Microbiol Lett 22, 289-295.

Rubens, C. E., Wessels, M. R., Heggen, L. M. \& Kasper, D. L. (1987). Transposon mutagenesis of type III group B Streptococcus: correlation of capsule expression with virulence. Proc Natl Acad Sci USA 84, 7208-7212.

Rubens, C. E., Heggen, L. M., Haft, R. F. \& Wessels, M. R. (1993). Identification of $c p s D$, a gene essential for type III capsule expression in group B streptococci. Mol Microbiol 8, 843-855.

Salasia, S. I. O., Lämmler, C. \& Herrmann, G. (1995). Properties of a Streptococcus suis isolate of serotype 2 and two capsular mutants. Vet Microbiol 45, 151-156.

Sambrook, J., Fritsch, E. F. \& Maniatis, T. (1989). Molecular Cloning: a Laboratory Manual, 2nd edn. Cold Spring Harbor, NY: Cold Spring Harbor Laboratory.

Smith, H. E., Vecht, U., Wisselink, H. J., Stockhofe-Zurwieden, N., Biermann, Y. \& Smits, M. A. (1996). Mutants of Streptococcus suis types 1 and 2 impaired in expression of muramidase-released protein and extracellular protein induce disease in newborn germfree pigs. Infect Immun 64, 4409-4412.

Tikkanen, K., Haataja, S. \& Finne, J. (1996). The galactosyl-( $\alpha 1-4)-$ galactose-binding adhesin of Streptococcus suis: occurrence in strains of different hemagglutination activities and induction of opsonic antibodies. Infect Immun 64, 3659-3665.

Trottier, S., Higgins, R., Brochu, G. \& Gottschalk, M. (1991). A case of human endocarditis due to Streptococcus suis in North America. Rev Infect Dis 13, 1251-1252.

Vecht, U., Wisselink, H. J., Jellema, M. L. \& Smith, H. E. (1991). Identification of two proteins associated with virulence of Streptococcus suis type 2. Infect Immun 59, 3156-3162.

Walsh, B., Williams, A. E. \& Satsangi, J. (1992). Streptococcus suis type 2: pathogenesis and clinical disease. Rev Med Microbiol 3, $65-71$.

Warren, L. (1963). Thiobarbituric acid assay of sialic acids. Methods Enzymol 6, 463-464.

Wessels, M. R., Moses, A. E., Goldberg, J. B. \& DiCesare, T. J. (1991). Hyaluronic acid capsule is a virulence factor for mucoid group A streptococci. Proc Natl Acad Sci USA 88, 8317-8321.

Williams, A. E. (1990). Relationship between intracellular survival 
in macrophages and pathogenicity of Streptococcus suis type 2 isolates. Microb Pathog 8, 189-196.

Williams, A. E., Blakemore, W. F. \& Alexander, T. J. (1988). A murine model of Streptococcus suis type 2 meningitis in the pig. Res Vet Sci 45, 394-399.
Received 17 June 1997; revised 29 September 1997; accepted 1 October 1997. 